\title{
RESENHA DO LIVRO GÊNERO, MASCULINIDADES E DIVERSIDADE: EDUCAÇÃO FÍSICA, ESPORTE E IDENTIDADES MASCULINAS
}

BOOK REVIEW: GENDER, MASCULINITY AND DIVERSITY: PHYSICAL

EDUCATION, SPORT AND MASCULINE IDENTITIES

RESENHA DEL LIBRO GÉNERO, MASCULINIDADES Y DIVERSIDAD:

EDUCACIÓN FÍSICA, DEPORTE E IDENTIDADES MASCULINAS

Rafael de Gois Tinoco*, Mayara Cristina Mendes Maia*, Paula Nunes Chaves*, Rondinele Souza Santana*, Allyson Carvalho Araújo*

Palavras-chave

Diversidade cultural.

Masculinidade.

Sexismo.

Keywords

Cultural diversity.

Masculinity.

Sexism.

\section{Palabras clave}

Diversidad cultural.

Masculinidad.

Sexismo
Resumo: Esta resenha tem como objetivo apresentar e analisar o livro Género, masculinidades y diversidad: educación física, deporte e identidades masculinas, organizado por Joaquín Piedra de la Cuadra, publicado pela ediciones Octaedro, no ano de 2013 na cidade de Barcelona, Espanha
Abstract: This review has the goal of presenting and analyzes the book Género, masculinidades y diversidad: educación física, deporte e identidades masculinas, organized by Joaquín Piedra de la Cuadra, published by ediciones Octaedro, in 2013, in the city of Barcelona, Espanha.

Resumen: Esta revisión tiene como objetivo presentar y analizar el libro Género, masculinidades y diversidad: educación física, deporte e identidades masculinas, organizado por Joaquín Piedra de la Cuadra, publicado por Ediciones Octaedro, en 2013, en Barcelona, España.
* Universidade Federal do Rio Grande do Norte. Natal, RN, Brasil. E-mail: rafaeldegois@ hotmail.com

Recebido em: 29-06-2015 Aprovado em: 14-10-2015 (c) (1) (8) Licence 
A tradição dos estudos de gênero relacionados à Educação Física e esportes tem, historicamente, seu vínculo centrado na reflexão das reivindicações das mulheres nestes espaços de práticas sociais, alimentando-se em grande medida do movimento e teoria feminista entre os anos 60/70 do século passado para fortalecer seu pensamento (GOELLNER, 2007). A principal consequência desse perfil da literatura específica foi o desenvolvimento marginal dos debates sobre masculinidades, homofobia e diversidades.

A partir do mapeamento do campo percebe-se uma emergência relativamente recente dos estudos que descentraram da reflexão da mulher nas práticas corporais no Brasil (PEREIRA et al., 2015). Destacadamente a produção, circulação e consumo da produção que abarca a temática da masculinidade têm se concentrado em âmbito anglo-saxão e pouco dialogado com pesquisadores das sociedades mediterrâneas, sul-americanas e mulçumanas.

Neste cenário, o livro Género, masculinidades y diversidad: educación física, deporte e identidades masculinas, organizado por Joaquín Piedra de la Cuadra, busca dar respostas a duas lacunas na circulação da produção sobre gênero. A primeira diz respeito à necessidade de dar visibilidade às temáticas das distintas expressões de masculinidade e seus desdobramentos de respeito à diversidade, especificamente no tocante à homofobia; e a segunda faz referência ao fomento desse debate em países de língua de raiz latina, que tem encontrado literatura científica reduzida. Para tanto, a publicação conta com 18 pesquisadores de diversos países, a fim de incitar discussões sobre masculinidade e diversidade.

Desse modo, Joaquín Piedra, investigador espanhol com formação (inicial e continuada) e atuação na Universidad de Sevilla, tem concentrado esforços para pensar a coeducação, sobretudo a partir de temas de gênero e discriminação. Também tem se consolidado como pesquisador de temáticas inclusivas no âmbito da Educação Física e do Esporte, com outras obras como: Coeducación Física: aportaciones para uma nueva cultura de género (2014); capítulos de livros Analysis of homophobia during Physical Education lessons in Spain (2014a); além de artigos como Visibilizando lo invisible: creencias del profesorado de Educación Física sobre homofobia y masculinidades (2014b). Essas produções ${ }^{1}$ são todas do ano de $2014 \mathrm{e}$ demonstram o debruçar desse investigador sobre a problemática em questão.

Especificamente na obra Género, masculinidades y diversidad: educación física, deporte e identidades masculinas (2013), Joaquín Piedra de la Cuadra aponta a marginalidade dos temas relacionados às masculinidades nos estudos de gênero. $E$, ao fazê-lo, esclarece que a ditadura do patriarcado também tem oprimido as diversas expressões de masculinidade, além de problematizar esse aspecto no âmbito da educação. Estes argumentos, a nosso ver, justificam teoricamente a pertinência da obra após uma percepção do estado da arte relacionado ao tema.

A legitimidade da temática se dá na medida em que as aulas de Educação Física e o próprio contexto escolar se constituem espaços eficazes de expressões e consolidações dos estereótipos dominantes de masculinidade. Sendo necessário, assim, fomentar uma educação que desconstrua esses padrões e potencialize a igualdade, evitando qualquer forma de violência e favorecendo o diálogo na resolução de conflitos.

A obra em questão é constituída por 12 capítulos divididos em três partes para articular temas que transversalizam a masculinidade e a homossexualidade, a homofobia como tema 
de investigação emergente na Educação Física, além de contextualizar em diferentes países os investimentos do debate da masculinidade na Educação Física.

No intuito de tensionar as possibilidades de transformação do ambiente educacional em um espaço de problematização da masculinidade hegemônica e da presença de atitudes homofóbicas, o livro traz dois capítulos (2 e 8) que se relacionam por serem experiências pedagógicas. Reservadas as diferenças do contexto das experiências, a primeira realizada em uma classe britânica de 6ำ ano e a outra em centros educacionais públicos de Madri com alunos de $5^{\circ}$ e 6ำ ano, em que ambas buscaram a superação do quadro de discriminação por caminhos diversos, é possível que essa diversidade de caminhos se deva ao olhar distintivo de quem assina o texto, tendo em vista que na primeira experiência são dois autores britânicos e, na segunda experiência, duas autoras espanholas.

Apesar dos temas abordados se conectarem, na primeira intervenção fica clara uma ênfase dos autores quanto à homofobia velada, visto que as discussões partiram do silenciamento e da opressão sexual e de gênero nos sistemas escolares, enquanto estratégia de validação de um capital heteromasculino, apontando a homofobia enquanto ferramenta importante para a vigilância das masculinidades. Já na segunda intervenção, as autoras dão respaldo à formação e afirmação das identidades masculinas no âmbito da Educação Física, da atividade física e do esporte, a partir de discussões sobre identidade masculina em oposição à identidade feminina.

Com propósito de ratificar a necessidade de maiores debates acerca dessas temáticas, os capítulos 6, 7 e 9 discorrem, principalmente, sobre o conceito de masculinidade hegemônica. Centrados nos estudos de Connell (1987;1995), estes capítulos problematizam as representações e práticas que constituem a referência socialmente legitimada de como deve ser a vivência do homem masculino. Essa discussão se configura fundamental no momento em que o pensar uma masculinidade singular, geralmente, dificulta a percepção da variedade e riqueza das experiências de masculinidades, incorrendo no risco de nos tornarmos fundamentalistas e, portanto, cair na intolerância e no desrespeito.

Seja em contexto português, argentino ou sueco as argumentações dos autores deste bloco, a partir de suas peculiaridades, centram-se no objetivo de desconstruir a visão de gênero, ora pondo em questão o perfil masculinizado da Educação Física desde sua raiz histórica até suas expressões contemporâneas de dominação da masculinidade hegemônica, ora evidenciando que esta problemática advém de um cenário mais amplo. Nessa direção, a evidência desse cenário mais abrangente se dá a partir da constatação de que na oportunidade do ingresso dos meninos na escola já se observam padrões construídos e reconstruídos, advindos de outros meios, como família, meios de comunicação e amigos.

Problematizando sobre os padrões construídos e reconstruídos pelo meio familiar, mídia e/ou pelos amigos, os capítulos 5 e 10 enfatizam o processo de construção social e cultural da masculinidade diante de um padrão hegemônico e de estereótipos veiculados. 0 capítulo 5 evidencia as imagens publicitárias dos brinquedos na Espanha e suas inclinações em relacionar meninas à beleza e estética e meninos a objetos bélicos, arquétipo do guerreiro e brinquedos de locomoção. Nesses termos, considerando a mídia como uma pedagogia indireta e produtora de sentidos para seus espectadores, é importante considerar que, especialmente a publicidade, através de seu universo simbólico, reproduz tendências sociais que definem atitudes, comportamentos e ideias. Essas reproduções delimitam os papéis masculinos e 
femininos, transformando as relações de gênero no princípio estruturante das demais (ROSA; FERREIRA, 2014).

Já o capítulo 10 evidencia práticas das comunidades masculinas na estrutura do âmbito social da Educação Física dos colégios turcos, que ressaltam a masculinidade dominante e marginalizam aqueles que não estão de acordo com essa dominância reforçada pelos laços patriarcais, em um modelo de subserviência ditado pelo patriarcado nas instituições educacionais. Nesse sentido, Scott (1995) já anunciava que o gênero está entrelaçado à organização social e é resultado de delineamentos políticos. Destarte, a combinação entre saber e poder municia aparatos para lidar com as diferenças sexuais ao ver a conjuntura dos processos de dominação e de subordinação em suas mais variadas causas.

A obra em questão ainda se ocupa em questionar a falta de estudos que ofereçam uma perspectiva internacional para compreender a relação entre determinadas práticas corporais, tais como a dança e a masculinidade. Neste sentido, Michael Gard (2013) realiza um panorama histórico que liga o bailarino à homossexualidade, sugerindo-o como um horizonte de investigação fértil. A agenda de pesquisa apontada pelo autor australiano ganha legitimidade ao compreendermos que classificar um indivíduo como homem ou mulher significa marcar o seu corpo culturalmente, e, para isso acontecer, é preciso que condutas regulatórias de gênero e sexualidade sejam constantemente reiteradas (LOURO, 2004). Dito isso, é importante realçar que a dança está dentre as várias práticas sociais em que os corpos são marcados por discursos de gênero e sobre sexualidade, ou seja, os usos desses podem ser analisados como mecanismos de controle e de aplicação das normas sobre bailarinos.

Fazendo alusão à Educação Física Escolar, o texto trata do ensino da dança nas aulas, denunciando a marginalização desse conteúdo e reivindicando a defesa de um resgate, colocando os alunos como partícipes do processo de decodificação dos significados dos movimentos.

Acreditamos que, também no Brasil, o ensino da dança na escola é cenário de vários descompassos pedagógicos/culturais. Nessa perspectiva, as aulas de Educação Física têm sido um espaço de rotulações de atividades para meninos e meninas, em que a dança está marcada como atividade feminina e os esportes como masculina em detrimento de uma proposta de formação cultural que seja capaz de tensionar atividades corporais como mediadoras de atitudes de respeito mútuo, dignidade e solidariedade. Nesses termos, o ensino de Educação Física na escola tem se distanciado do ideal de valorização e respeito da pluralidade de manifestações da cultura corporal (BRASIL, 1998).

Aantítese darepresentaçãofeminina da dançatambéméabarcadanaobraerepresentada pela reificação masculina dos esportes. No capítulo quarto os autores problematizam os estereótipos que marcam o corpo do atleta ao esgarçar a limitada compreensão do corpo da mulher no esporte como flexível e atrativo, enquanto o do homem como representado pelo poder físico e muscular. À revelia dessas representações, Sousa e Altmann (1999) apontam que, apesar da participação feminina ter aumentado significativamente, o contexto esportivo se mantém envolto por valores masculinos. Assim, a marcação dicotômica dos corpos de homens e mulheres atletas faz, geralmente, com que as mulheres esportistas sejam vítimas de questionamentos, preconceitos e estereótipos provenientes de diversos espaços da sociedade em geral. 
Na intenção de exemplificar essa vitimização a partir da construção da imagem corporal, esse capítulo traz o caso da Caster Semenya, evidenciando o dilema da representação da mulher atleta em afirmar uma imagem corporal ao mesmo tempo feminina e valorizada no cenário competitivo. As autoras, ao trazerem a percepção de universitários sobre os estereótipos do corpo da mulher atleta, diagnosticam a conservação de estereótipos sexistas sobre ele.

A obra em questão ainda se ocupa em fazer inferências sobre a postura dos professores espanhóis sobre a homossexualidade e a homofobia existentes nas aulas de Educação Física, além de problematizar junto com alunos de Educação Física do ensino médio as percepções que os jovens espanhóis têm sobre os acontecimentos de homofobia e heterossexismo nas aulas de Educação Física.

Nesses capítulos é interessante notar que, apesar do contexto espanhol demonstrar avanços relevantes acerca da legislação que aborda a igualdade de tratamento e não discriminação em matéria da homossexualidade e masculinidade no âmbito educativo, evidencia-se paralelamente que falta uma longa caminhada ao respeito à diversidade. $E$ isso se deve bastante à pouca atuação dos professores no uso de atitudes inclusivas e a não interferência em momentos de discriminação.

Louro (2004a) evidencia que questões referentes ao corpo, gênero e sexualidade normalmente têm ganhado espaços para se firmarem nas escolas e que é neste cenário que as relações sociais tensionam os preconceitos, aproximações, discriminações e resistências, estas, em última instância, são negociadas, construídas e fixadas. A partir dessa constatação é possível elucubrar que, não somente na Espanha, o processo educacional inclusivo encontrase em gradativo e lento progresso no que se refere à pluralidade de expressão, encontrando barreiras atitudinais diante da arbitrariedade de padronização social dos corpos, desejos e prazeres.

Ao término da degustação da obra, que articula argutamente um denso arcabouço teórico com empiria sensata e sensível às demandas da diversidade, compreendemos que "[...] assim como se aprende também se pode desaprender que as desigualdades e os processos de subordinação não são inevitáveis nem naturais" (SCHARAGRODSKY, 2003, p. 182). Com a obra é possível aprender, com relatos de diversas partes do mundo, que, academicamente e em intervenções pedagógicas, ainda temos um longo caminho a percorrer no Brasil sobre os debates de gênero e sexualidade, sobretudo nos que dão relevo às diversas masculinidades possíveis de serem expressas na Educação Física e nos esportes.

A sugestão de leitura é um convite para os que aceitam o desafio de pensar de forma um pouco mais marginal. Distante da percepção negativa do termo, o convite ao pensamento marginal ancora-se na prática de um pensamento que opera pelas margens, como um movimento transgressor em um campo tão marcadamente disciplinador como historicamente tem se apresentado o campo da Educação Física e dos esportes. Portanto, se o silenciar das múltiplas masculinidades foi regra, a reflexão a partir da obra em tela propõe a necessidade de um deslocamento de sentido, um olhar na contramão para pensar os diversos sujeitos descentrados que habitam as práticas corporais.

Convidamos a todos para uma agradável leitura que poderá fortalecer o repertório acionado pelos pesquisadores brasileiros na argumentação em favor da diversidade. 


\section{REFERÊNCIAS}

BRASIL, Secretaria de Educação Fundamental. Parâmetros Curriculares Nacionais: Educação Física. Brasília: MEC, 1998.

CONNELL, Raewyn William. Gender and Power. Stanford: Stanford University, 1987.

CONNELL, Raewyn William. Masculinities. Cambridge: Polity, 1995.

GARD, Michael. Danza, masculinidad y educación física: una perspectiva internacional. In: PIEDRA DE LA CUADRA, Joaquín. Género, masculinidades y diversidad: educación física, deporte e identidades masculinas. Barcelona: Octaedro, 2013. p. 61-79.

GOELLNER, Silvana Vilodre. A educação dos corpos, dos gêneros e das sexualidades e 0 reconhecimento da diversidade. Cadernos de Formação RBCE, Porto Alegre, v. 1, n. 2, p. 71-83, mar. 2010.

GOELLNER, Silvana Vilodre. Feminismos, mulheres e esportes: questões epistemológicas sobre 0 fazer historiográfico. Movimento, Porto Alegre, v. 13, n. 2, p. 171-196, maio/ago. 2007.

LOURO, Guacira Lopes. Gênero, Sexualidade e Educação: uma perspectiva pós-estruturalista. Petrópolis: Vozes, 2004.

LOURO, Guacira Lopes. Um corpo estranho: ensaios sobre sexualidade e teoria queer. Belo Horizonte: Autêntica, 2004a.

PEREIRA, Erik Giuseppe Barbosa et al. Os estudos de gênero e masculinidade e seus reflexos para a Educação Física. Revista Brasileira de Ciência e Movimento, Taguatinga, v. 23, n. 1, p. 146-156, jan./mar. 2015.

PIEDRA DE LA CUADRA, Joaquín. Género, masculinidades y diversidad: educación física, deporte e identidades masculinas. Barcelona: Octaedro, 2013.

PIEDRA DE LA CUADRA, Joaquín. Coeducación Física. Aportaciones para una nueva cultura de género. Saarbrücken: Académica Española, 2014.

PIEDRA DE LA CUADRA, Joaquín et al. Analysis of homophobia during Physical Education lessons in Spain. In: TODARO, Ricky. Handbook of Physical Education Research: Role of School Programs, Children's Attitudes and Health Implications. New York: Nova Publishers, 2014a.

PIEDRA DE LA CUADRA, Joaquín; MACÍAS, Gonzalo Ramírez; ROMERO, Agueda Latorre. Visibilizando lo invisible: estudio de casos de las creencias del profesorado de educación física sobre homofobia y masculinidades. Retos Nuevas Tendencias em Educación Física, Deporte y Recreación, Logroño, n. 25, p. 36-42, jan.jun. 2014b.

ROSA, Mariana Andrade Barcelos; FERREIRA, Eliane Schmaltz. Gênero e mídia: as representações sociais do feminino na publicidade das revistas Nova e Playboy. Caderno Espaço Feminino, Uberlândia, v. 27, n. 1, p. 1-21, jan.jjun. 2014.

SCHARAGRODSKY, Pablo Ariel. Masculinidades en movimiento en las clases de educación física argentinas, o acerca de cómo no quedar en off side. In: PIEDRA DE LA CUADRA, Joaquín. Género, masculinidades y diversidad: educación física, deporte e identidades masculinas. Barcelona: Octaedro, 2013. p.160-185.

SCOTT, Joan Wallach. Gênero: uma categoria útil de análise histórica. Educação \& Realidade, Porto Alegre, v. 20, n. 2, p. 71-99, jul./dez. 1995.

SOUSA, Eustáquia Salvadora de; ALTMANN, Helena. Meninos e Meninas: expectativas corporais e implicações na Educação Física Escolar. Cadernos Cedes, Campinas, v. 19, n. 48, p. 52-68, ago. 1999. 